\title{
Potential Mechanism of Herb-Drug Interaction Mediated by Angelica dahurica: Inhibition on CYP3A Enzymes in Rats
}

\author{
Fan Yang*, Ally R. Mussa*, Lijun An, Rongjia Liang, Xiaoyan Shi, Justin N. Kabera, Xin He\# \\ School of Chinese Materia Medica, Tianjin University of Traditional Chinese Medicine, Tianjin, China \\ Email: "hexintn@163.com
}

Received 26 February 2016; accepted 17 April 2016; published 20 April 2016

Copyright (C) 2016 by authors and Scientific Research Publishing Inc.

This work is licensed under the Creative Commons Attribution International License (CC BY).

http://creativecommons.org/licenses/by/4.0/

(c) (i) Open Access

\begin{abstract}
Angelica dahurica is commonly referred to as 'Baizhi' in China and has been noted for its therapeutic significance. The major active ingredients of Angelica dahurica is coumarin, which is reported as a kind of potent inhibitor of cytochrome P450 enzymes (CYP450s). The aim of this study was to investigate the inhibition of CYP3A enzymes by total coumarin extract (TCE) obtained from dried root of Angelica dahurica by using in situ single pass intestinal perfusion (SPIP) and in situ liver perfusion in rats. When midazolam (MDZ) which is a substrate of CYP3A co-perfused with TCE $(198 \mu \mathrm{g} / \mathrm{mL})$ from Baizhi in duodenum and ileum segments, the $P_{\text {eff }}$ of MDZ has increased significantly compared with the MDZ single perfused group $(p<0.01)(n=6)$. However, there was no significant effect on $P_{\text {eff }}$ of MDZ when it co-perfused with $66 \mu \mathrm{g} / \mathrm{mL}$ of TCE from Baizhi in both segments $(p>0.05)(n=6)$. During in situ liver perfusion study, the results demonstrated that, 3 days oral administration of TCE obtained from Baizhi could significantly reduce the elimination rate of MDZ in the perfusate $(p<0.05)(n=3)$. This study revealed that TCE from Baizhi had potent inhibition on CYP3A enzymes, and the inhibitory effect was related to dose. Therefore, when Angelica dahurica extract co-administrated with drugs which are the substrates of CYP3A, much more attention should be paid rather than that of other CYP450 enzymes. These findings may facilitate in predicting possible herb-drug interactions (HDIs) when Angelica dahurica is used in combination with other drugs, and decrease the incidence of the CYP450-mediated HDIs.
\end{abstract}

\section{Keywords}

Angelica dahurica, Total Coumarin Extract (TCE), Inhibition, CYP3A, Herb-Drug Interactions (HDIs)

\footnotetext{
${ }^{*}$ These authors contributed equally to this work.

"Corresponding author.
}

How to cite this paper: Yang, F., Mussa, A.R., An, L.J., Liang, R.J., Shi, X.Y., Kabera, J.N. and He, X. (2016) Potential Mechanism of Herb-Drug Interaction Mediated by Angelica dahurica: Inhibition on CYP3A Enzymes in Rats. Pharmacology \& Pharmacy, 7, 153-161. http://dx.doi.org/10.4236/pp.2016.74020 


\section{Introduction}

Medicinal herbs have been used to treat a variety of health conditions since ancient times. With the increased use of herbal medicines, research spotlight on the possibility of herb-drug interactions (HDIs) has become imperative.

Angelica dahurica (FISCH) Benth et Hooker F. referred to as 'Baizhi' in China is one of the most popular traditional Chinese medicines (TCM) with the history of more than 2000 years for treating frontal headache, toothache, rhinitis, boils, carbuncles, and skin diseases in clinics [1] [2]. There have been reported that Baizhi has anti-inflammatory, antioxidant, and inhibition on cytochrome P450 enzymes (CYP450s) activity [3]. Baizhi extract suppressed hepatic testosterone hydroxylation in human and rat at positions $2 \alpha, 16 \beta$, and $6 \beta$. These reactions are catalyzed by CYP2C11, CYP3A and CYP1A respectively in human, and CYP2C11, CYP2B and CYP3A respectively in rat [1] [4]. Baizhi extract inhibited the effect of CYP2C, CYP3A, and CYP2D in rat liver microsomes by decreasing the metabolic activity of tolbutamide, nifedipine and bufuralol, respectively. It also delayed the elimination of diazepam and nifedipine after intravenous administration in rats [1] [4]. These enzymes are important for metabolism of drugs and xenobiotics [5].

The major active constituents of this plant are coumarins and furocoumarins such as byak-angelicol, oxypeucedanin, imperatorin, cnidilin, phellopterin and isoimperatorin. Isoimperatorin is often used as the standard in the quality control of Baizhi [2] [3]. In the past decade, coumarins and its derivatives have been the focus of research due to their diverse pharmacological properties such as anti-inflammatory, antioxidant, anticoagulant, antifungal, antibacterial, antitumor, anticonvulsant and anti-hyperglycemic properties [6]. The data obtained from the previous investigations using in vivo and in vitro methods for studying coumarin compounds such as 6', 7'-dihydroxybergamottin, bergamaottin, begaptol, psoralen, isopsoralen, imperatorin, isoimperatorin, and trioxsalen suggested that these compounds can inhibit or induce a wide range of CYP subtypes, including CYP1A1/2, CYP2A2, CYP2A6, CYP2B6, CYP2D6, CYP2C19, CYP2E1, CYP3A4 and/or p-glycoprotein [7]-[11].

Inhibition of drug-metabolizing enzymes, especially CYP450s, is regarded as the most frequent and clinically important issues among the possible causes for HDIs. CYP3A, the most abundant CYP in liver and intestine, is responsible for metabolism of more than $50 \%$ of clinically used drugs, and variations in its catalytic activity are important in issues of drug-drug interactions [12]. The aim of this study was to investigate the inhibition of CYP3A enzyme by TCE from Angelica dahurica radix using in situ single pass intestinal perfusion (SPIP) and in situ liver perfusion models in rats, so that Baizhi can be used safely.

\section{Materials and Methods}

\subsection{Chemical Material}

Midazolam (MDZ), ketoconazole (KTC) (>98\% purity), and D-glucose were purchased from Sigma Chemical Co. (St. Louis, MO). The HPLC grade solvents methanol (MeOH), formic acid (FA), and orthophosphoric acid $\left(\mathrm{H}_{3} \mathrm{PO}_{4}\right)$ were obtained from Fisher Chemica, and water was purified by the Milli-Q system (Millipore Corp., USA). Physiological saline solution was purchased from Hospira Inc. (Lake Forest, IL). All other chemicals were of analytical grade.

\subsection{Animals}

Age-matched male albino Sprague-Dawley rats, weighing 200 - 350 g, were purchased from the Animal Experiment Laboratory, Tianjin Institute of Pharmaceutical Research. Prior to each experiment, the rats were fasted overnight for 12 - $18 \mathrm{~h}$, with free access to water, and randomly assigned to the experimental groups.

\subsection{Preparation of Total Coumarin Extract (TCE) from Baizhi}

A total of $1 \mathrm{~kg}$ Baizhi was extracted with $8 \mathrm{~L}$ of $75 \%$ ethanol under reflux for $1.5 \mathrm{~h}$ three times. The extract was concentrated under reduced pressure using a rotary evaporator at $50^{\circ} \mathrm{C}$. The dry powder was pulverised using macroporous resin as follows: seven times water, eight times 30\% ethanol and eight times $75 \%$ ethanol. A solution of $75 \%$ ethanol was obtained and evaporated to dryness. Preliminary analysis about this extracts was done by using a validated and reverse phase high performance liquid chromatography (HPLC) system (Agilent 1260 Infinity LC; Agilent Technologies Inc., USA), with a quaternary pump model G1311C. The chromat-ographic 
separation was carried out on Agilent Zorbax HC-C 18 column $(4.6 \mathrm{~mm} \times 250 \mathrm{~mm} \times 5 \mu \mathrm{m})$ (Agilent, USA). The mobile phase comprised A (methanol) and B (pure water) using a gradient elution of $40 \% \mathrm{~A}-90 \% \mathrm{~A}$ at $0-30$ $\min , 90 \% \mathrm{~A}-40 \% \mathrm{~A}$ at $30-30.5 \mathrm{~min}, 40 \% \mathrm{~A}$ at $30.5-36 \mathrm{~min}$. The flow rate was $1.0 \mathrm{~mL} / \mathrm{min}$ and the UV wavelength was $310 \mathrm{~nm}$.

\subsection{In Situ Intestinal Perfusion}

The in situ SPIP procedure has been optimized [13] [14]. Briefly, rats were anesthetized by administrating urethane $(1.4 \mathrm{~g} / \mathrm{kg}$, i.p. $)$, and then each rat was placed on a thermal insulation blanket to maintain their body temperature at $37^{\circ} \mathrm{C}$, which was measured by inserting a thermometer into the rectum. The rats were kept under a warming light during all experiments. A $3-4 \mathrm{~cm}$ midline abdominal incision was made, and the common bile duct was ligated, to minimize the effect of enterohepatic circulation of the drugs. Approximately $10 \mathrm{~cm}$ of the duodenum and ileum segments was carefully exposed; one end was connected to flexible polyvinyl chloride tubing, and another end was connected to a smooth glass tube. The isolated segments were rinsed using a syringe containing a Krebs-Ringer buffer $(\mathrm{KRB})(\mathrm{pH} 6.8)$ at $37^{\circ} \mathrm{C}$ that consisted of $\mathrm{NaCl}(7.8 \mathrm{~g} / \mathrm{L}), \mathrm{NaHCO}_{3}(1.37$ $\mathrm{g} / \mathrm{L})$, d-glucose $(1.4 \mathrm{~g} / \mathrm{L}), \mathrm{KCl}(0.35 \mathrm{~g} / \mathrm{L}), \mathrm{NaH}_{2} \mathrm{PO}_{4}(0.32 \mathrm{~g} / \mathrm{L}), \mathrm{CaCl}_{2}(0.37 \mathrm{~g} / \mathrm{L}), \operatorname{and~} \mathrm{MgCl}_{2}(0.042 \mathrm{~g} / \mathrm{L})$.

To examine the influence of TCE from Baizhi on the intestinal disposition of MDZ, 24 rats were divided equally into four groups, and each group was perfused with $30 \mu \mathrm{g} / \mathrm{mL}$ of MDZ diluted in KRB solution with or without KTC and TCE from Baizhi. Whereas one group perfused with only $30 \mu \mathrm{g} / \mathrm{mL}$ of MDZ as the blank control, one group perfused with solution of MDZ $(30 \mu \mathrm{g} / \mathrm{mL})$ and $\mathrm{KTC}(32 \mu \mathrm{g} / \mathrm{mL})$ as the positive control, the other two groups perfused with solution of MDZ $(30 \mu \mathrm{g} / \mathrm{mL})$ and TCE from Baizhi $(198 \mu \mathrm{g} / \mathrm{mL}$ or $66 \mu \mathrm{g} / \mathrm{mL})$.

The initiation of perfusion began with a 30 minutes perfusion at a flow rate of $0.2 \mathrm{~mL} / \mathrm{min}$ without collection the perfusate to reach a steady state. MDZ $(30 \mu \mathrm{g} / \mathrm{mL})$ with or without KTC $(32 \mu \mathrm{g} / \mathrm{mL})$ and TCE from Baizhi $(198 \mu \mathrm{g} / \mathrm{mL}$ or $66 \mu \mathrm{g} / \mathrm{mL})$ were prepared in the KRB. Then, the perfused samples were collected at 10 minutes intervals for a total of 90 minutes.

The surgical area was covered with a wet pledget, and drops of saline $\left(37^{\circ} \mathrm{C}\right)$ were added to the pledget to avoid disturbing the circulatory system during the whole perfusion process. The test tubes used in the sample collection were weighed before and after collection. The collected samples were transferred into $1.5 \mathrm{~mL}$ Eppendorf tubes and immediately were centrifuged and analyzed or stored at $-20^{\circ} \mathrm{C}$ until further HPLC analysis. At the end of the experiment, the perfused intestinal segments were sliced along the axis without stretching the organ, and carefully opened along the mesenteric root. The width and the length of the intestinal segment were measured and recorded as accurately as possible, and the animals were euthanized by cervical dislocation.

\subsection{In Situ Liver Perfusion}

To examine the influence of TCE from Baizhi on the hepatic disposition of MDZ, 9 rats were divided equally into three groups, and each group was perfused with $30 \mu \mathrm{g} / \mathrm{mL}$ of MDZ diluted in KHB solution. Whereas one group served as the blank control, the other two groups served as treatments. For positive control, KTC (20 $\mathrm{mg} / \mathrm{kg}$, i.p.) was administrated to rats for 3 days. For inhibition study, TCE (50 mg/kg, i.g.) was administrated to rats for 3 days.

A previously developed in situ liver perfusion method was used with minor modifications [14]-[16]. Briefly, male Sprague Dawley rats (200 - $350 \mathrm{~g})$ were anesthetized using urethane (1.4 g/kg, i.p.) prior to surgery, after 3 days administration of KTC (20 mg/kg, i.p.) or TCE $(50 \mathrm{mg} / \mathrm{kg}$, i.g). Then a "V" cut was made on the abdomen, the hepatic portal vein and superior vena cava were exposed and cannulated, the cranial vena cava and the common bile duct ligated. The livers were perfused in situ with oxygenated Krebs-Hensleit Buffer (KHB) (pH $7.4)$ at $37^{\circ} \mathrm{C}$ that consisted of $\mathrm{NaCl}(6.92 \mathrm{~g} / \mathrm{L}), \mathrm{KCl}(0.35 \mathrm{~g} / \mathrm{L}), \mathrm{CaCl}_{2}(0.28 \mathrm{~g} / \mathrm{L}), \mathrm{KH}_{2} \mathrm{PO}_{4}(0.16 \mathrm{~g} / \mathrm{L}), \mathrm{MgSO}$ $(0.223 \mathrm{~g} / \mathrm{L}), \mathrm{NaHCO}_{3}(2.1 \mathrm{~g} / \mathrm{L})$, and d-glucose $(3.0 \mathrm{~g} / \mathrm{L})$ at a flow rate of $20 \mathrm{~mL} / \mathrm{min}$ to provide sufficient oxygen-carrying capacity.

The KHB buffer was pumped through the liver by roller pump via the portal vein, the abdominal vena cava was incised immediately after perfusion had begun, and the dripping polyethylene tube ( $2 \mathrm{~mm}$ i.d., $3 \mathrm{~mm}$ o.d.) was inserted. The thorax was opened then, and the thoracic vena cava was ligated.

Then the flow rate was changed to $10 \mathrm{~mL} / \mathrm{min}$, after 20 minutes which was the optimal time for the liver to stabilize, the buffer solution containing MDZ was added to the reservoir, the temperature was maintained at $37^{\circ} \mathrm{C}$ through the use of a warming light and a heating carpet, the volume was determined gravimetrically (spe- 
cific gravity 1.0), then a sample was taken immediately at 0min and the KHB buffer without drug was allowed to flow back to the reservoir. The re-circulating perfusate $(0.5 \mathrm{~mL})$ was taken at $1,2,3,4,5,10,15,25,40,60$ $\mathrm{min}$, and the same volume of KHB buffer without drug was added in the reservoir each time when samples were taken. Samples were immediately centrifuged and analyzed or were stored at $-20^{\circ} \mathrm{C}$ until further HPLC analysis.

\subsection{HPLC Analysis}

Quantification of MDZ in samples were determined by isocratic mode, using a validated and reverse HPLC system (Agilent 1260 Infinity LC; Agilent Technologies Inc., USA), with a quaternary pump model G1311C. All analyses were performed on an analytical Agilent $\mathrm{HC}_{-} \mathrm{C}_{18}$ column $(250 \mathrm{~mm} \times 4.6 \mathrm{~mm} ; 5 \mu \mathrm{m})$, protected with an Agilent $\mathrm{HC}-\mathrm{C}_{18}$ pre-column $(30 \mathrm{~mm} \times 4.6 \mathrm{~mm} ; 5 \mu \mathrm{m})$ maintained at $25^{\circ} \mathrm{C}$. The mobile phase consisted of methanol and $0.5 \%$ formic acid at a ratio of $53: 47(\mathrm{v} / \mathrm{v})$, the flow rate and injection volume was $0.9 \mathrm{~mL} / \mathrm{min}$ and 20 $\mu \mathrm{L}$, respectively. Method validation of the selectivity, precision, accuracy, linearity, and stability were conducted to ensure the feasibility of the analytical method.

\subsection{Statistical Analysis}

The SPIP is based on reaching steady state with respect to the diffusion of compound across intestine. Steady state is confirmed by plotting the ratio of the outlet to inlet concentrations (corrected for water transport) versus time. The equation below was used to calculate the efficient permeability $\left(P_{e f f}\right)$ through the rat intestinal wall in the SPIP using the "plug flow" model, also known as radial mixing model [14] [17].

The equation was expressed as follows;

$$
P_{\text {eff }}=-Q \operatorname{In} \frac{C_{\text {out }} Q_{\text {out }}}{C_{\text {in }} Q} /(2 \pi r L)
$$

where $C_{\text {in }}$ and $C_{\text {out }}$ are the concentration of MDZ entering and leaving the intestinal segments respectively; $Q$ and $Q_{\text {out }}$ are the flux of perfusate entering and leaving the intestinal segments; $r$ is the radius of the perfused intestinal segments; and $L$ is the measured length of the intestinal segments perfused.

The change of drug concentration in the liver perfusion was determined by detecting the concentration of MDZ in perfusate at different time $(0,1,2,3,4,5,10,15,25,40,60 \mathrm{~min})$. Then we draw a graph with a curve of time vs concentration. Results are obtained by comparing the control group curve with the curves of the remaining groups.

\section{Results}

\subsection{Identification of Major Coumarins in TCE from Baizhi}

The major coumarins in Baizhi extract were quantified and the percentages of imperatorin, xanthotoxol, 5-hydroxy-8-methoxy psoralen, oxypeucedanin hydrate, bergapten, imperatorin, cnidilin and isoimperatorin were $2.36 \%, 2.50 \%, 2.58 \%, 1.24 \%, 7.80 \%, 8.74 \%$ and $4.86 \%$, respectively. HPLC fingerprint chromatogram of TCE from Baizhi is shown in Figure 1. The total coumarins ( $>52 \%$ in the extract) was determined by UV spectroscopy. The chemical structures of these seven ingredients are shown in Table 1.

\subsection{Inhibition of TCE from Baizhi on CYP3A in Intestine}

As shown in Figure 2, the result of SPIP experiment showed that the $P_{\text {eff }}$ of MDZ increased significantly when co-perfused with KTC in both duodenum and ileum segments $(\mathrm{p}<0.05)$. The TCE from Baizhi also increased the $P_{\text {eff }}$ of MDZ markedly when co-perfused in both segments. Compared with the MDZ single perfused group, the dose of $66 \mu \mathrm{g} / \mathrm{mL}$ of TCE from Baizhi showed no significant effect on MDZ $P_{\text {eff }}$ in both segments, while the $P_{\text {eff }}$ of MDZ increased very significantly $(\mathrm{p}<0.01)$ when co-perfused with the dose of $198 \mu \mathrm{g} / \mathrm{mL}$ of TCE from Baizhi in both segments. And there was significant difference of effect in MDZ $P_{\text {eff }}$ between $66 \mu \mathrm{g} / \mathrm{mL}$ of TCE and $198 \mu \mathrm{g} / \mathrm{mL}$ of TCE in duodenum segment $(\mathrm{p}<0.05)$. In ileum segment, the difference was obviously shown in the graph though there was no significant difference through statistic analysis ( $p$ value was 0.06 ), Thus, both the TCE from Baizhi and KTC significantly increased the permeability of MDZ, and the effect of TCE from Baizhi was related to dose. 


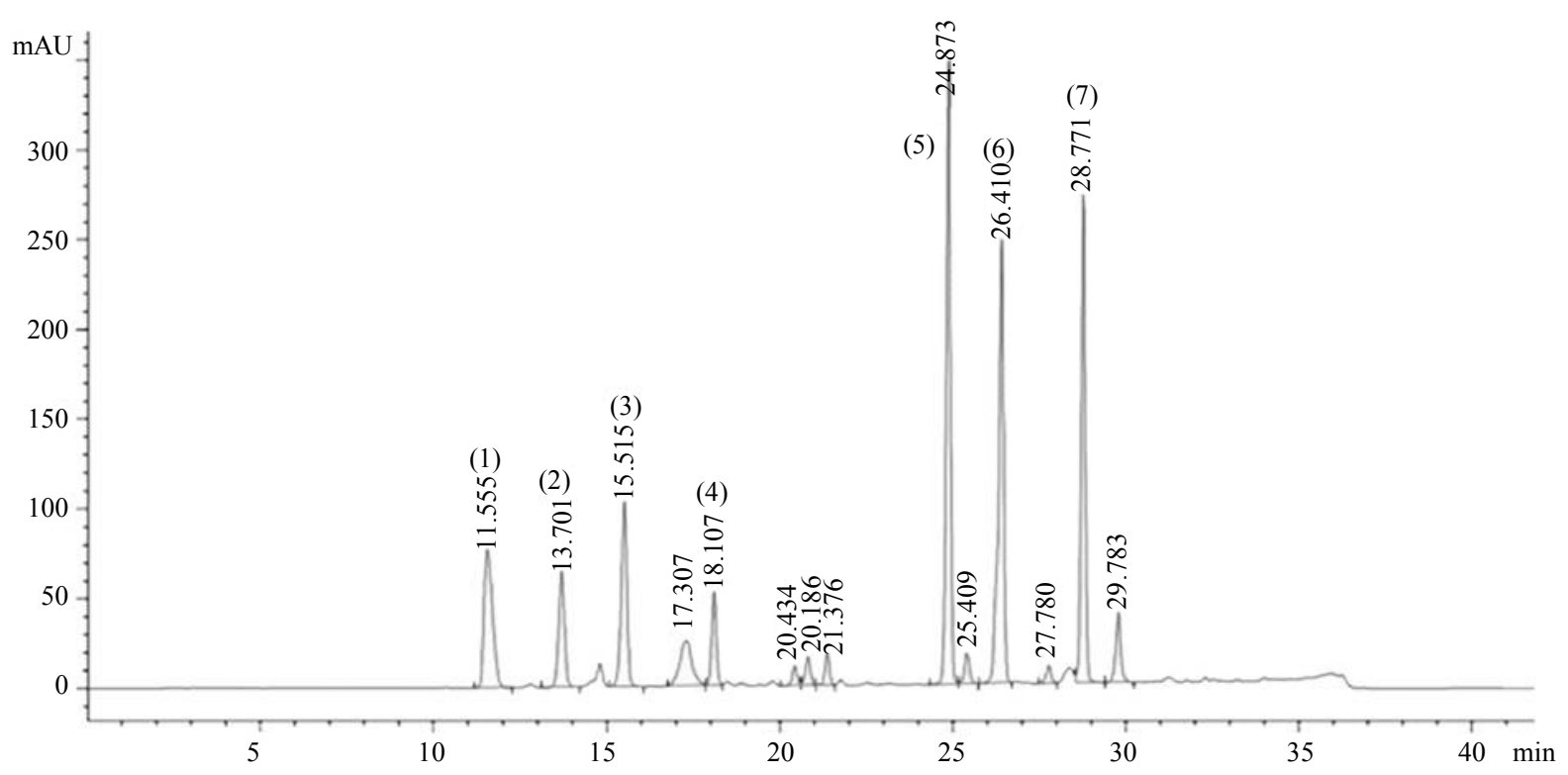

Figure 1. HPLC fingerprint chromatogram of TCE from Baizhi. (1) xanthotoxol; (2) 5-hydroxy-8-methoxy psoralen; (3) oxypeucedanin hydrate; (4) bergapten; (5) imperatorin; (6) cnidilin and (7) isoimperatorin in TCE.

Table 1. Chemical structures of major cumarins in TCE from Baizhi.

(3) oxypeucedanin hydrate

\subsection{Inhibition of TCE from Baizhi on CYP3A in Liver}

The result (Figure 3) of in situ liver perfusion experiment showed that MDZ was substantially metabolized in the liver during the perfusion when it was perfused singly. After the rats were administrated with KTC (20 $\mathrm{mg} / \mathrm{kg}$, i.p.) for 3 days, the concentration of MDZ in the perfusate reduced to a level less than that of the MDZ single perfused group during the liver perfusion ( $\mathrm{p}<0.05)$. After 3 days administration of TCE $(50 \mathrm{mg} / \mathrm{kg}$, i.g.) 


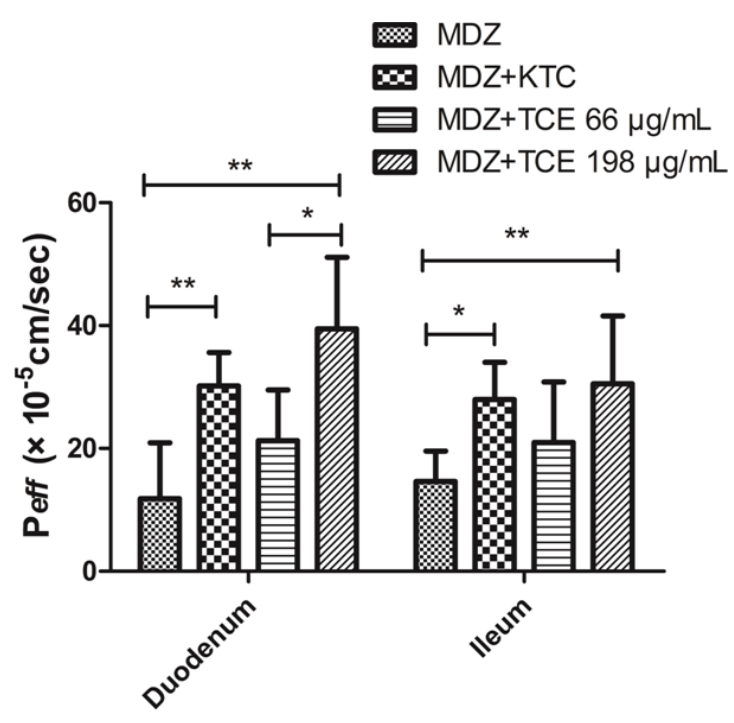

Figure 2. $P_{\text {eff }}$ of MDZ obtained from in situ SPIP in Duodenum and Ileum segment with/without KTC (inhibitor) and TCE from Baizhi. Values are expressed as means \pm SD $(n=6)$. Notes: ${ }^{*} p<0.05,{ }^{* *} p<0.01$.

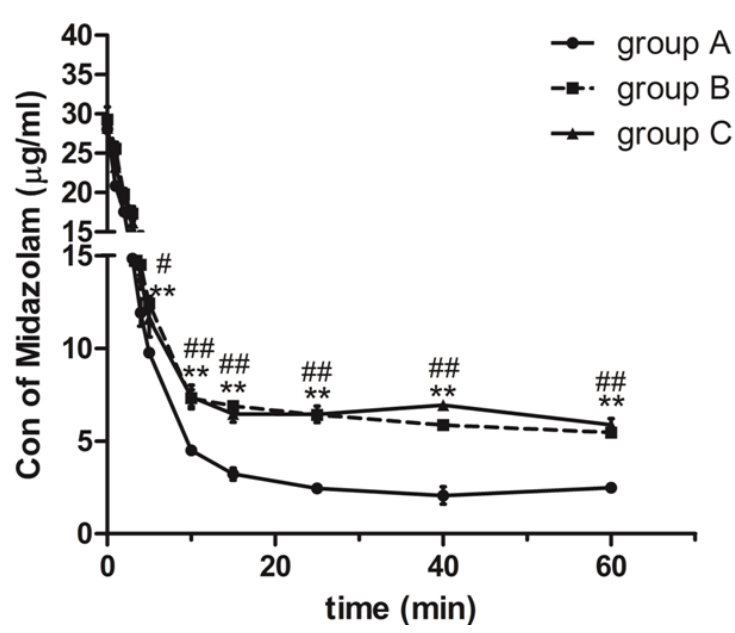

Figure 3. Influence of the CYP3A inhibitor KTC and TCE from Baizhi on the concentration of MDZ in the liver perfusate. Values are expressed as means \pm SD ( = 3). Notes: group A: perfused MDZ single; group B: perfused MDZ after administrated KTC (20 mg/kg, i.p.) for 3 days; group C: perfused MDZ after administrated TCE (50 mg/kg, i.g.) for 3 days; *p $<0.05, * * p<0.01$ (group B vs group A); \#p $<0.05$, \#\#p $<0.01$ (group C vs group A).

from Baizhi, similar effect was observed compared to that obtained after administration of KTC $(p<0.05)$. Hence, both TCE from Baizhi and KTC significantly reduced the elimination rate of MDZ in the perfusate within 60 minutes.

\section{Discussion}

HDI is one of the most important clinical concerns in the consumption of herbs and prescription drugs. The ability of intestinal and hepatic CYP to metabolize numerous drugs is responsible for the large number of docu- 
mented drug-drug and drug-food interactions [18]. Herbal products usually contain a mixture of pharmacologically active phytochemicals, most of which are secondary metabolites [1] [18]. These phytochemicals have been classified into three main classes such as, terpenoids, alkaloids and phenolic compounds [19]. This complexity may increase clinical herb-drug interactions.

In clinic, a number of HDIs have been reported involving drug metabolic enzymes and transporters. Herbal medicine and its constituents are not as safe as previous thought. They may cause either potential inhibition or activation of drug metabolic enzymes and/or transporters which may lead to HDIs [14].

Possible in vivo drug-drug interactions are often inferred from in vitro studies with liver enzymes. The correlation of in vitro results with in vivo behavior has yielded reliable results in certain cases in terms of in vivo predictability. However the extent of clinical significance is poorly inferable. Thus, in the present study, the inhibition of CYP3A enzymes by TCE from Angelica dahurica radix was investigated using two in vivo methods (SPIP and liver perfusion) in rats, to explore the possibility of HDIs with CYP3A probe MDZ.

In situ intestine perfusion has been proven to be an accurate method for evaluating the permeability of chemicals. The results of in situ SPIP from our study showed that the inhibitor of CYP3A, KTC, increased the $P_{\text {eff }}$ of MDZ both in duodenum and ileum segments significantly $(\mathrm{p}<0.05)$, and TCE from Baizhi achieved the samilar effect as KTC. This suggested that TCE from Baizhi may be also an inhibitor of CYP3A. The dose of 198 $\mu \mathrm{g} / \mathrm{mL}$ of TCE from Baizhi showed a significant inhibition on CYP3A enzymes in both duodeum and ileum segments $(p<0.01)$. However there were no significant inhibitory effects when perfused with a dose of 66 $\mu \mathrm{g} / \mathrm{mL}$ of TCE from Baizhi $(\mathrm{p}>0.05)$. This indicated that the inhibitory effect of TCE from Baizhi is related to dose.

Furthermore, the liver perfusion results showed that TCE from Baizhi can significantly inhibit the CYP3A enzymes. It markedly reduced the elimination rate of CYP3A probe drug MDZ in the perfusate $(p<0.05)$, and KTC showed similar effect as observed in TCE from Baizhi notably $(\mathrm{p}<0.05)$. According to the results in this study, the inhibition of TCE from Baizhi on CYP3A enzymes was markedly observed in the liver. However, in the intestine, only high dose of TCE from Baizhi showed significant inhibition on CYP3A. This could be due to the higher expression of CYP3A enzymes in the liver compared to the mucosal epithelium of the intestine [20] [21].

Moreover, CYP3A enzymes are implicated in the first-pass metabolism of several drugs which are the substrate of CYP3A including MDZ [22]. MDZ is almost metabolized to 1'-hydroxymidazolam, 4-hydroxymidazolam, and 1',4-dihydroxymidazolam with less than 3\% excreted into urine unchanged [23] [24]. And MDZ has been a valuable tool for the measurement of metabolic activity of the CYP3A subfamily in rats (CYP3A1/2) as well as in human (CYP3A4/5) [21] [22] [25] [26].

It has been previously reported that the oral administration of Baizhi extract suppressed hepatic testosterone hydroxylation in human and rat at positions $2 \alpha, 16 \beta$, and $6 \beta$; which were catalyzed by human CYP2C11, CYP3A and CYP1A, respectively [4], and CYP2C11, CYP2B and CYP3A in rat, respectively [1]. Additionally, Baizhi extracts have been shown to inhibit the activities of CYP2C, CYP3A, and CYP2D in rat liver microsomes by decreasing the metabolic activity of tolbutamide, nifedipine and bufuralol, respectively. The multiple oral dosage showed a decrease in metabolic ratio of caffeine which is catalyzed by CYP1A2 in human [1].

According to our results, TCE from Baizhi suppressed the activity of CYP3A subfamily in rats. Thus, this study revealed a possible mechanism of HDI which leads by Baizhi, and this kind of HDI is noteworthy.

\section{Conclusion}

This study demonstrated that TCE from Angelica dahurica radix (Baizhi) may affect the metabolism of drugs which are the substrates of the CYP3A isoform. Therefore, when Angelica dahurica extract co-administrated with drugs which are the substrates of CYP3A, much more attention should be paid rather than that of other CYP450 enzymes, and further in vivo experiments are required to evaluate the inhibition of CYP3A by TCE from Angelica dahurica radix on human CYP450 enzymes.

\section{Acknowledgements}

This work was supported by the National Natural Science Foundation of China (81373890); The Research Fund for the Masters Program of Higher Education (20121210110011); The Program for Changjiang Scholars and Innovative Research Team in University (No. IRT_14R41). 


\section{References}

[1] Yi, S.J., Joo-Youn, C., Soo, L.K., Kyu-Pyo, K., Jaewoo, K., Bo-Hyung, K., et al. (2009) Effects of Angelicae Tenuissima Radix, Angelica dahurica Radix and Scutellariae Radix Extracts on Cytochrome P450 Activities in Healthy Volunteers. Basic \& Clinical Pharmacology \& Toxicology, 105, 249-256. http://dx.doi.org/10.1111/j.1742-7843.2009.00423.x

[2] Zhang, H., Gong, C.G., Lv, L., Xu , Y.J., Zhao, L., Zhu, Z.Y., Chai, Y.F. and Zhang, G.P. (2009) Rapid Separation and Identification of Furocoumarins in Angelica dahurica by High-Performance Liquid Chromatography with Diode-Array Detection, Time-of-Flight Mass Spectrometry and Quadrupole Ion Trap Mass Spectrometry. Rapid Communications in Mass Spectrometry RCM, 23, 2167-2175. http://dx.doi.org/10.1002/rcm.4123

[3] Lee, H., Lee, J.K., Ha, H., Lee, M.Y., Seo, C.S. and Shin, H.K. (2012) Angelica dahurica Radix Inhibits Dust Mite Extract-Induced Atopic Dermatitis-Like Skin Lesions in NC/NGA Mice. Evidence-Based Complementary and Alternative Medicine, 2012, 614. http://dx.doi.org/10.1155/2012/743075

[4] Ishihara, K., Kushida, H.M., Wakui, Y., Yanagisawa, T., Kamei, H., Ohmori, S., et al. (2000) Interaction of Drugs and Chinese Herbs: Pharmacokinetic Changes of Tolbutamide and Diazepam Caused by Extract of Angelica dahurica. Journal of Pharmacy \& Pharmacology, 52, 1023-1029. http://dx.doi.org/10.1211/0022357001774750

[5] Liska, D.J. (1998) The Detoxification Enzyme Systems. Alternative Medicine Review: A Journal of Clinical Therapeutic, 3, 187-198.

[6] Venugopala, K.N., Rashmi, V. and Odhav, B. (2013) Review on Natural Coumarin Lead Compounds for Their Pharmacological Activity. Biomed Research International, 2013, 563-568.

[7] Lian-Qing, G. and Yasushi, Y. (2004) Inhibition of Cytochrome P450 by Furanocoumarins in Grapefruit Juice and Herbal Medicines. Acta Pharmacologica Sinica, 2, 129-136.

[8] Ho, P.C., Saville, D.J. and Wanwimolruk, S. (2001) Inhibition of Human CYP3A4 Activity by Grapefruit Flavonoids, Furanocoumarins and Related Compounds. Journal of Pharmacy \& Pharmaceutical Sciences, 4, 217-227.

[9] Ohnishi, A., Matsuo, H., Yamada, S., Takanaga, H., Morimoto, S., Shoyama, Y., Ohtani, H. and Sawada, Y. (2000) Effect of Furanocoumarin Derivatives in Grapefruit Juice on the Uptake of Vinblastine by Caco-2 Cells and on the Activity of Cytochrome P450 3A4. British Journal of Pharmacology, 130, 1369-1377. http://dx.doi.org/10.1038/sj.bjp.0703433

[10] Yang, J., Hao, C., Yang, D., Shi, D., Song, X., Luan, X., et al. (2010) Pregnane X Receptor Is Required for Interleukin-6-Mediated Down-Regulation of Cytochrome P450 3A4 in Human Hepatocytes. Toxicology Letters, 197, $219-226$. http://dx.doi.org/10.1016/j.toxlet.2010.06.003

[11] Zhuang, X.M., Zhong, Y.H., Xiao, W.B., Li, H. and Lu, C. (2013) Identification and Characterization of Psoralen and Isopsoralen as Potent CYP1A2 Reversible and Time-Dependent Inhibitors in Human and Rat Preclinical Studies. Drug Metabolism \& Disposition, 41, 1914-1922. http://dx.doi.org/10.1124/dmd.113.053199

[12] Guengerich, F.P. (1998) Cytochrome P-450 3A4: Regulation and Role in Drug Metabolism. Annual Review of Pharmacology \& Toxicology, 39, 1-17. http://dx.doi.org/10.1146/annurev.pharmtox.39.1.1

[13] Dahan, A. and Amidon, G.L. (2008) Segmental Dependent Transport of Low Permeability Compounds along the Small Intestine Due to P-Glycoprotein: The Role of Efflux Transport in the Oral Absorption of BCS Class III Drugs. Molecular Pharmaceutics, 6, 19-28. http://dx.doi.org/10.1021/mp800088f

[14] Liang, S., Deng, F., Xing, H., Wen, H., Shi, X., Martey, O.N., et al. (2014) P-Glycoprotein- and Organic Anion-Transporting Polypeptide-Mediated Transport of Periplocin May Lead to Drug-Herb/Drug-Drug Interactions. Drug Design, Development \& Therapy, 8, 475-483.

[15] Chow, E.C.Y., Liu, L., Ship, N., Kluger, R.H. and Pang, K.S. (2008) Role of Haptoglobin on the Uptake of Native and $\beta$-Chain [Trimesoyl-(Lys82) $\beta$-(Lys82) $\beta$ ] Cross-Linked Human Hemoglobins in Isolated Perfused Rat Livers. Drug Metabolism \& Disposition, 36, 937-945. http://dx.doi.org/10.1124/dmd.107.019174

[16] Inoue, H., Tsuruta, A., Kudo, S., Ishii, T., Fukushima, Y., Iwano, H., Yokota, H. and Kato, S. (2005) Bisphenol a Glucuronidation and Excretion in Liver of Pregnant and Nonpregnant Female Rats. Drug Metabolism \& Disposition, 33, 55-59. http://dx.doi.org/10.1124/dmd.104.001537

[17] Fagerholm, U., Johansson, M. and Lennernäs, H. (1996) Comparison between Permeability Coefficients in Rat and Human Jejunum. Pharmaceutical Research, 13, 1336-1342. http://dx.doi.org/10.1023/A:1016065715308

[18] Fasinu, P.S., Bouic, P.J. and Rosenkranz, B. (2012) An Overview of the Evidence and Mechanisms of Herb-Drug Interactions. Frontiers in Pharmacology, 3, 69. http://dx.doi.org/10.3389/fphar.2012.00069

[19] Kabera, J.N., Semana, E., Mussa, A.R. and He, X. (2014) Plant Secondary Metabolites: Biosynthesis, Classification, 
Function and Pharmacological Properties. Journal of Pharmacy and Pharmacology, 2, 377-392.

[20] Mitschke, D., Reichel, A., Fricker, G., et al. (2008) Characterization of Cytochrome P450 Protein Expression along the Entire Length of the Intestine of Male and Female Rats. Drug Metabolism \& Disposition, 36, 1039-1045. http://dx.doi.org/10.1124/dmd.107.019687

[21] Takara, K., Ohnishi, N., Horibe, S., et al. (2003) Expression Profiles of Drug-Metabolizing Enzyme CYP3A and Drug Efflux Transporter Multidrug Resistance 1 Subfamily mRNAS in small Intestine. Drug Metabolism \& Disposition, 31, 1235-1239. http://dx.doi.org/10.1124/dmd.31.10.1235

[22] Gibbs, M.A., Thummel, K.E., Shen, D.D., et al. (1999) Inhibition of Cytochrome P-450 3A (CYP3A) in Human Intestinal and Liver Microsomes: Comparison of Ki Values and Impact of CYP3A5 Expression. Drug Metabolism \& Disposition, 27, 180-187.

[23] Juřica, J., Dostálek, M., Konečný, J., Glatz, Z., Hadašová, E. and Tomandl, J. (2007) HPLC Determination of Midazolam and Its Three Hydroxy Metabolites in Perfusion Medium and Plasma from Rats. Journal of Chromatography B, 852, 571-577. http://dx.doi.org/10.1016/i.jchromb.2007.02.034

[24] Sherry, T.C. (2013) Endogenous Biomarkers of CYP3A Activity. University of Washington, Seattle.

[25] Miroslav, D., Court, M.H., Bingfang, Y., et al. (2011) Significantly Reduced Cytochrome P450 3A4 Expression and Activity in Liver from Humans with Diabetes Mellitus. British Journal of Pharmacology, 163, 937-947. http://dx.doi.org/10.1111/j.1476-5381.2011.01270.x

[26] Kaoru, K., Kikuko, U., Noriaki, S. and Kan, C. (2002) Substrate Specificity for Rat Cytochrome P450 (CYP) Isoforms: Screening with cDNA-Expressed Systems of the Rat. Biochemical Pharmacology, 63, 889-896.

http://dx.doi.org/10.1016/S0006-2952(01)00843-7 